\title{
The Influence of the Client's Background on the Auditor's Decision in Acceptance the Audit Engagement
}

\author{
Marilena Mironiuc, Ionela-Corina Chersan and Ioan-Bogdan Robu
}

Alexandru Ioan Cuza University of Iasi, Romania

Correspondence should be addressed to: Marilena Mironiuc; marilena@uaic.ro

Received 28 February 2012; Accepted 25 March 2012; Published 28 March 2013

Academic Editor: Iuliana Eugenia Georgescu

Copyright (C) 2013 Marilena Mironiuc, Ionela-Corina Chersan and Ioan-Bogdan Robu. Distributed under Creative Commons CC-BY 3.0

\begin{abstract}
In financial auditing the auditor can accept a new engagement or not, based on the client's background, with a major impact on the audit risk. This study aims to indentify and analyze the influence of the background factors that lead the auditor to the clients' acceptance. For obtaining the research result, in the study a sample of 100 companies was considered. These companies were the first 100 multinationals included in top 500 Fortune, from 2011, and which were audited by Big 4 audit companies. The study develops three work hypotheses regarding the influence of some financial and non-financial factors to the auditor's acceptance of a new audit engagement. For testing the hypotheses, there were proposed as factors some financial variables (return ratios, financial leverage) and non-financial variables (activity field, auditor). The research results were obtained by using quantitative methods for data analysis. In the study the data were processed with the statistical software, SPSS 19.0. The research results show that the auditor's decision regarding the acceptance of the audit engagement is significantly influenced by the client's prestige, reflected through the position occupied in Top 500 Fortune, the specialization of the auditor in a specific activity field and by the client's financial performance and his ability to continue as a going concern in a predictable horizon of time.
\end{abstract}

Keywords: Audit engagement acceptance, client's background, prestige and financial performance, multiple correspondence analysis, discriminant analysis, logistic regression analysis.

\section{Introduction}

The great financial scandals before and post Sarbanes-Oxley Act (2002) attracted the attention of the public opinion and on the audit companies, being found responsible to the same extent, as the companies which have defrauded, for the financial losses (and not only) registered either at the national level, or at the global level (Ball, 2009). After these unfortunate events, some audit companies were brought before court, being compelled to pay considerable indemnifications or were even destroyed.

Normally, the qualified, objective and independent opinion of the auditor would 
have signaled the presence of some significant distortions within the annual financial statements. In this case Amernic and Craig (2004) indicate as main factors that led to the emergence of inadequate opinions, the complicity of auditors (in some situations) and also the high audit risk, registered at the level of mission (because of inappropriate preparation).

Based on the same opinion, Beattie et al. (2004) consider that the auditors' role is that of tempering the aggressiveness of companies in the financial report, and for this specialty technical knowledge of a high level is necessary, undoubted integrity and certain practical abilities.

Thus, in order to rehabilitate the image and the status, a series of normative acts were adopted and imposed by the profession at the international level (Ethics codes, Good Practices Codes, Supplementary Amendments to the audit standards) which aim at eliminating the incompatibility states (and which significantly threaten the auditor's independence) and the auditor's guidance, as regards his competence, for accepting a certain client for auditing (Stevenson, 2002).

The client acceptance criteria refer to the reduction of the audit risk through the previous knowledge of him and of the environment where he carries out the activity, with significant impact on the issuance of an opinion in conformity with reality, which leads to the increase of the mission quality (Hayes et al., 2005).

Thus, we must identify and analyze the main determining factors that significantly influenced the acceptance decision by the large Big 4 audit companies (formed of Price water house Coopers, Ernst \&Young, Deloitte, KPMG) of the first 100 companies of Top 500 Fortune 2011. The present study proposes to fundament a determinist model of evaluating the criteria through which the audit companies of the Big 4 group accepted into their client portfolio certain companies, according to a series of financial and non-financial factors. More than that, based on the identified factors we can also obtain a general profile of a client accepted by one of the Big 4 companies.

\section{Literature Review}

Normally, the request for the supply of audit services comes from the combination of four important theories, which imply the necessity of such services (Hayes et al., 2005). The first of them, The Policeman Theory brings into discussion the auditor's responsibility regarding the prevention and detection of financial frauds, although we can currently consider the fact that this no longer represents the main purpose of an audit (Dowler and Harris, 1912). The second, The Lending Credibility Theory is based on the large public's perception of the audit companies, their role being that of adding a plus of credibility to the financial situations (Hayes et al., 2005). The following, The Theory of Inspired Confidence, proposed at the end of the 1920s by Theodore Limperg, specifies the fact that the audit services must support the company external stakeholders' trust in the managers and their actions (Limperg Institute, 1985). The last is the Agency Theory, of Watts and Zimmerman, who consider the audit services ad being a component part of the monitoring activities within a company, significantly contributing to the reduction of the information bias between the principals and the agents (Watts and Zimmerman, 1978).

Concluding, we appreciate the fact that the set of the four theories justifies the importance of expressing an exact opinion regarding the accuracy of the reported financial accounts, for supporting the strategic decisions of all the stakeholders, and for increasing the prestige of the audit company.

Not lastly, Arrens and Loebbecke (2005) consider that the auditor's opinion is influenced by the audit risk that he is willing to accept, and the quantity and quality of evidence elements based on which he fundaments his opinion. Thus, the reduction of the audit risk takes into account the knowledge, the understanding and the control of its components: the 
inherent risk - specific to the environment where the audited company carries out its activity, the control risk - taking into account the efficiency of the control system in preventing and detecting the significant distortions and the and the non-detection risk - associated to the auditor from the perspective of its capacity and professional training in detecting certain significant distortions (Hayes, 2005). Based on the preliminary analysis of the incidence of the three risk factors, the auditor will assess the extent to which he will accept a new client or renew the mandate, appreciating at the same time the value of the nondetection risk assumed (IFAC, 2009).

\section{Accepting the Client, Preliminary Stage within the Financial Audit Engagement}

Considered by Hayes et al. (2005) as being the first step within the audit process, the acceptance stage of a company as customer by the auditor is an extremely important one, with impact on the mission costs and on the auditor's reputation as well (IFAC, 2010).

In his study, Gendron (2001) specifies the fact that the decision of accepting a client is a stage within the audit process and is a resultant of the compromise achieved between the auditor's professional logic and the commercial logic it is subject to by virtue of the competition on the market of audit services.

The Theory of resource dependency, developed by Pfeffer and Salancik (1978) is focused on the same direction, but applied to the audit field. It suggests that the auditors, in order to ensure the profitability of his activities and even in order to survive, directly depend on the fees paid by their clients. In this context, we must mention the fact that the statutory audit missions represent a legal obligation but not a vital necessity for the customer company.

Although most of the times the commercial pressure has a significant influence, the audit companies and the profession have developed a series of mechanisms that ensure the accomplishment of the independence and professional competence criteria (IFAC, 2010).

In order to maintain the independence and the competitiveness on the profile market, Greenstein and Hamilton (1997) consider that the audit companies should change their customer acceptance strategy and the professional reasoning must be supported by the use of expert systems for taking decisions regarding the acceptance or rejection of a client.

Within this stage, the auditor must take into account all the reasons that would lead to the acceptance or refusal of the client through a series of procedures regarding: the previous knowledge of the customer's business environment, evaluating the incompatibility situations and the professional competence ones, communicating with the previous auditor, and in the final part preparing and signing the engagement letter (IFAC, 2010).

The practice has proven however the fact that some audit companies refused to sign commitments with the companies that did not present the proof of complying with the legal or ethical norms (Hayes et al., 2005). The refusal to accept was also formulated in the case that the potential client presented a high risk at the level of the branch of activity, which would have led to the increase of mission costs (Johnstone, 2000). We thus notice a tendency of the audit companies to run from the eventual expensive problems generated by the acceptance of certain clients, although the audit service market is an extremely competitive one.

McFadden (2003) starts from the implications of the large financial scandals on the auditors and considers necessary to impose certain audit politics and procedures that lead to the minimization of the risk associated with the client's integrity and to that associated to the auditor (as regards the professional competition). For this, the auditor must be interested in the customer's integrity and the factors influencing it (the type of client, the type of service supplied by the auditor, the use by the client and of other consultancy services). 
Some studies (McFadden, 2003) reveal the fact that the acceptance of a client is also determined by the auditor's competence (although he may resort to the services of other specialists/auditors) and the resources that he has for minimizing the audit risk (Fukukawa et al., 2011).

Hayes et al. (2005) considers that until the acceptance of a client, the audit mission responsible must take into account the ensurance of a sufficient training level (either theoretical or technical) of the audit team, the experience of the team members (the participation to similar missions), the compliance with the legal and contractual terms (as regards the issuance of the opinion from the audit report) and also the possibility of applying the professional reasoning (to the extent to which this is allowed or not). All these must take into account the specificity of the object of activity of the potential client.

Another factor of influence on the decision of acceptance analyzed by Basioudis (2007) is represented by alumni effect. The influence of this factor on the audit market is manifested due to the presence of the former auditors in the managing board of the customer companies and who facilitate their acceptance for auditing, and also the payment of reduced commissions, although most of the times this practice leads the audit companies to the exposal to litigations generated by the clients.

Based on the things mentioned above, we can conclude that the acceptance of a company to be audited depends both on a series of factors controlled by the auditor (independence, competence, prestige), and on a series of specific factors for the potential client. For this reason, the auditor must analyze the client's background elements that can influence his decision of accepting the auditing.

\section{Background Factors that Influence the Auditor's Decision to Accept the Client}

Within the client's preliminary knowledge, Bragg (2010) and Fukukawa et al. (2011) appreciate that the evaluation of his background elements allow the determination of the accepted audit risk level and also the manner in which the auditor will plan his entire mission. For obtaining information regarding the client's background, Hayes et al. (2005) proposes the access of some public sources of information (databases and governmental sites and of syndicate associates, mass-media articles), using the auditor's own experience (files and previous reports) and requesting supplementary information from the client (minutes, financial statements, internal audit reports etc.). The modalities of analyzing these sources can vary, according to the purpose aimed at by the auditor, from advanced selections in the databases, to questionnaires and discussions with the client company representatives (Hayes et al., 2005).

The IFAC code (2010) regarding the client's acceptance presents a series of elements of interest for the auditor regarding the background evaluation. Among them, Ebaid (2011) considers that the auditor must give a special attention to the manner in which the client applies the corporatist governance principles (the organizational structure, the constitution of the managing board and the changes within). The IFAC code (2010) emphasizes however the importance of noticing the significant modifications in the activity of the client, and as regards the juridical framework applied by the Client, Niemi (2002) analyzes its impact on the company activity through the occurrence of the eventual litigations. At the same time, the auditor must analyze as well the evolution of the business environment where the company is integrated, the eventual financial problems that the company is confronted with, the suspicions regarding the occurrence of errors and of financial frauds, changes from the financialaccounting, information and internal control system (Porter et al., 2003).

In this regard, the client company must put at the auditor's disposal general information regarding the registered office of the group, the locations where it carries out its activity, the object of activity, the 
composition of the managing board, the relationship with the banks and other creditors, and the information regarding the previous auditor (Soltani 2005). For the client's acceptance, the auditor's decision must also rely on the financial information regarding the volume of assets, current debts, long term debts, own capitals, treasury flows (net and from exploitation), incomes and size of the net result (Pickett, 2006).

At the same time, they must be correlated with the standards of financial reporting used and with the other legal provisions that the client company applies, the auditor thus having the possibility to decide based on which standards he will achieve the audit mission (IFAC, 2010).

Not lastly, Hayes et al. (2005) claims in his work that the auditor must be interested in the general reputation of the company in the business environment where it acts (based on certain classifications), in the integrity of the managers and the other members responsible with governance.

Another important element that must be taken into account by the auditor is represented by the entity's capacity to continue its activity. From the point of the view of the financial elements, Porter et al. (2003) claims that its evaluation must take into account the financial analysis of the main profitability rates, the scoring analysis, the analysis of the production level correlated with that of supply and distribution of finite products/merchandises, the credit analysis and the analysis of the stock exchange and company shares evolution.

\section{Research Methodology}

Within the present study, we propose to analyze and quantify the influence of certain financial and non-financial factors on the decision of acceptance of a client by the audit companies from the Big 4 group. Based on the determinant factors we can obtain an acceptance profile and a series of classification functions of the clients according to the object of activity, certain profitability and performance indicators at the market level, on each audit company, member of the Big 4 .

More than that, the study proposes to fundament a model for determining the probability of a company traded on a financial international market to be accepted by a certain auditor member of the Big 4 group, according to the financial and non-financial indicators taken into consideration in the study. These profiles, classification functions and models of probability calculations can be useful to the auditors in supporting the decision regarding the acceptance or refusal of a client, as preliminary analytical procedures).

For achieving the research objective, we propose a methodological demarche of positivist type. This demarche aims at testing and validating a general hypothesis (obtaining some qualitative and quantitative models for supporting the auditor's decision - company member of the Big 4, to accept or refuse a client) at the level of a sample of representative companies (Smith, 2010).

\section{Developing the Work Hypotheses}

According to the work methodology (IFAC, 2010) and the (International Standards on Auditing - ISA) proposed by IFAC (2009), the acceptance of a client to be audited must also be supported by the background preliminary analysis, from the perspective of the financial performance and the capacity to continue the activity in a predictable period of time (Hayes et. al. 2005). For this, Soltani (2003), Porter et al. (2003) and Arens et al. (2012) propose the use of the financial indicators that also describe the client's financial performance under the form of analytical procedures. However, reporting ourselves to ISA 520 Analytical Procedures (IFAC, 2009), their application for obtaining an understanding of the entity and the client's work environment takes into account the achievement of comparisons at the level of branch of activity/sector or level or periods analyzed. 
According to Mironiuc's opinion (2006), the performance has the significance of a prestigious result of a special achievement, and in the business environment conceived it acquires the connotation of success, in the general plan or according to specific fields of activity of the company, with the help of the set of consecrated indicators.

In evaluating the performances of a company, Penman (2007) proposes the use of profitability rates (economic Return on Operating Assets - ROA, financial Return on Equities - ROE, commercial Net Margin NM, of invested capitals Return on Invested Capital ROIC).

According to Bragg (2007), ROA indicates the efficiency of using the exploitation assets for obtaining the operational result, and ROE illustrates the net result generated by the own invested capitals. At the profitability level, $N M$ is defined as the ratio between the net result and the total sales (Fabozzi et al., 2003), and Walsh (2003) defines ROIC as the extent to which the gross result remunerates the totality of invested capitals (own or foreign). In the case of a high-performance company, the ROIC value must be higher than the value registered by the weighted average cost of capitals (Weighted Average Cost of Capital WACC). Not lastly, Penman (2007) considers that these profitability rates must be correlated also with the ration between the total debts and the total capitals, based on the financial leverage (FL) analysis.

Based on the things presented, we consider that obtaining a profile and mathematical models for accepting a client by the auditor, using the profitability rates can be useful in the preliminary assessment. Thus, we propose to test and validate the following work hypotheses:

H1: At the level of the analyzed sample, we can individualize a profile of the client of one of the four audit companies, members of Big 4. This profile is achieved based on some financial indicators (profitability rates and liability structure) and non- financial (object of activity and position in top 500 Fortune). In the present study, we propose to identify this profile.

H2: Based on the values of the financial and non-financial indicators taken in the study, at the level of the analyzed sample we can obtain a score function that classifies the companies according to the belonging to a certain audit company, member of the Big 4. Thus, within the study, we propose to estimate the model parameters, which will indicate at the same time the importance of each indicator taken into account in achieving the classification.

H3: According to the values of the financial and non-financial indicators taken into account in the study, at the level of the analyzed sample we can obtain a function of estimating the probability to be accepted by one of the companies members of Big 4 . We thus propose to estimate the parameters of the functions of determining the acceptance probability by a certain audit company, member of Big 4 .

\section{Target Population and Extracting the Analyzed Sample}

Within the present study, the target population that we want to know is represented by the multinational companies present in top 500 Fortune, since 2011. From this population, for testing the work hypotheses we extracted a sample formed of 100 companies, the modality of extraction being of cluster type (the first 100 companies were selected, except the companies that activate in the sector of investment funds and insurances). Moreover, the sample was divided into three groups: the first echelon (contains the first 30 companies in the top), the second echelon (contains the following 30 companies) and the third echelon (contains the last 40 companies of top 500 Fortune).

Knowing the analyzed sample according to the object of activity of the companies allowed its structuring into three main categories, according to Figure 1. 


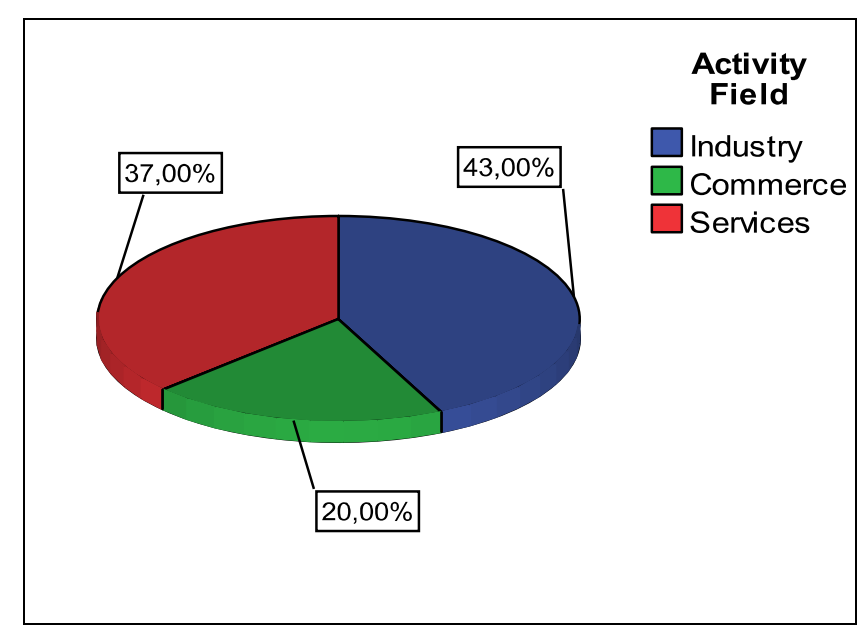

Fig 1. The Structure of the Sample Extracted according to the Activity Field of the First 100 Companies of Top 500 Fortune 2011

(Source: own processing in SPSS 19.0)

Grouping the companies according to the object of activity took into account the testing of work hypotheses according to this factor as well. At the same time the companies were divided into three large categories, according to their object of activity: industry, commerce and services.

\section{Analyzed Variables and Data Source}

For testing the work hypotheses, within the study, we proposed a series of factor variables (object of activity, financial leverage and profitability rates). For evaluating the global performance, we took into account the position of the company in Top 500 Fortune at the level of years 2011 and 2010. It should be mentioned that in the achievement of the Fortune classification for 2011, we took into account the financial statements of companies from 2010, and for the classification from 2010, we used the financial statements from 2009. According to these variables and knowing the auditor (company member of Big 4) that the company had signed the commitment for auditing the financial statements from 2010, the work hypothesis were validated (obtaining the profiles, the classification functions and those for determining the probability that a company is accepted by a certain auditor). The variables taken into account in the study are synthesized in the following table:

Table 1: The Factor Variables Taken into Account in the Study

\begin{tabular}{|l|l|l|}
\hline Variables & \multicolumn{1}{|c|}{ Calculation model } & \multicolumn{1}{c|}{ Significance } \\
\hline ROA & $(\mathrm{OI} / \mathrm{TA}):$ Operating Income/Total Assets & Return on Total Assets \\
\hline ROE & $(\mathrm{NR} / \mathrm{TE}):$ Net Result/Total Equity & Return on Equity \\
\hline ROIC & $\begin{array}{l}\left.\text { (OI/ } \mathrm{A}_{\mathrm{t}}\right): \text { Operating Income/Total Invested } \\
\text { Capital }\end{array}$ & Return on Invested Capital \\
\hline NM & $(\mathrm{NI} / \mathrm{TS}):$ Net Income/Revenue & Net Margin \\
\hline FL & $(\mathrm{TD} / \mathrm{TE}):$ Total Debts/Total Equity & Financial Leverage \\
\hline
\end{tabular}

(Source: own processing)

Obtaining the proposed profiles in the work hypotheses is possible only by transforming the factor variables taken into account in categorical variables. The transformation represents a statistical process of obtaining value categories for a certain variable, according to a certain criterion (Jaba and Grama, 2004). Based on the demarche proposed by Jaba and Grama (2004) and using Penman (2007) and Mironiuc (2006) criteria for obtaining the value categories of the financial rates, we obtained the new independent variables in SPSS, synthesized in Table 2. 
Table 2: The Transformed Categorical Variables

\begin{tabular}{|l|l|}
\hline Variables & \multicolumn{1}{|c|}{ Categories according to value intervals } \\
\hline Ctg_ROA & $1-$ ROA Critical $\in(-\infty ; 0] ; 2-$ ROA Average $\in(0 ; 0,1] ; 3-$ ROA High $\in(0,1 ;+\infty)$. \\
\hline Ctg_ROE & $1-$ ROE Critical $\in(-\infty ; 0] ; 2-$ ROE Average $\in(0 ; 0,1] ; 3-$ ROE High $\in(0,1 ;+\infty)$. \\
\hline Ctg_ROIC & $\begin{array}{l}1-\text { ROIC Critical } \in(-\infty ; 0] ; 2-\text { ROIC Average } \in(0 ; 0,1] ; 3-\text { ROIC High } \in(0,1 ; \\
+\infty) .\end{array}$ \\
\hline Ctg_NM & $1-$ NM Critic $\in(-\infty ; 0] ; 2-$ NM Average $\in(0 ; 0,1] ; 3-$ NM High $\in(0,1 ;+\infty)$. \\
\hline Ctg_FL & $1-$ FL Normal $\in[0 ; 2] ; 2-$ FL Risky $\in(2 ; 4] ; 3-$ FL Critic $\in(-\infty ; 0) U(4 ;+\infty)$. \\
\hline
\end{tabular}

(Source: own processing)

The data for the analyzed companies were collected from the EDGAR database of Securities and Exchange Commission (SEC), which contains the financial statements for the years 2009-2010.

\section{The Data Analysis Methods}

Within the study for achieving the research objectives, through the validation of work hypotheses, we propose the use of some data analysis methods, among which: the ratios technique (RT), the multiple correspondences analysis (MCA), the discriminant analysis (DA) and the logistical regression analysis (LRA).

$T R$ is a specific method of financial analysis and consists in calculating and interpreting some indices, determined through the reporting of some items or aggregates of items from the financial statements, afferent of the same financial year, for appreciating the state of a company (Mironiuc, 2006).

For obtaining the customer acceptance profiles, we propose the use of $M C A$. This is a multivariate analysis method, developed for the first time by Benzécri in 1969, for the study of associations between three or several nominal variables (categorical), being a generalized variant of the correspondence analysis (Lebart at al., 2006). For a sample of $n$ individuals, we dispose of values registered for a series of $m$ associated variables, based on which we can obtain the profile of an individual from a certain group, after the study of associations between the analyzed variables. This method synthesizes the initial information through the study of associations between the variables emphasized through a dispersion diagram built on a system of hierarchy factorial axes in decreasing order, according to their importance at explaining the total variation of the cloud of points. The method allows the obtaining of factorial axes, which characterize the profile dimensions. In the study, the two dimensions represented are a linear combination of the analyzed categorical variables, according to the frequencies of occurrence of the characteristics of each considered variable.

Obtaining the classification functions is based on the use of discriminant analysis (DA). Jaba and Robu (2009) claim that DA is a multivariate classification method, which was initially proposed by Fisher in 1936 for differentiating the individuals belonging to the same species according to a series of specific characteristics. By $D A$ we aim to classify the population into predefined groups, based on score functions $(Z)$ which express the relations between the independent variables, $X_{i}$, and the categories of classification variables. The relationship between the categorical dependent variable and the linear combinations of several independent variables of metrical type is presented under the form:

$$
Z=\beta_{0}+\beta_{1} X_{1}+\beta_{2} X_{2}+\ldots+\beta_{n} X_{n}
$$

At the model level, $Z$ is the calculated score, $X_{i}$ with $(i=1, \ldots, n)$ are the independent variables, and $\beta_{i}$ are the model coefficients (unknown). Each company $i$ can be associated to a score calculated based on the individual values of the $X_{i}$ variables. According to the value of the obtained score, a company can be classified into a class or another of the categorical variable 
(in the present case, from an auditor or another). The methodological demarche or DA supposes: obtaining the discriminant functions (as a linear combination of $X_{i}$ ), identifying the independent variables that best contribute to explaining the differences between the groups, classifying the individuals with predictive purpose by allotting them to a certain group according to the score obtained, starting from specified values of the $X_{i}$ variables and evaluating the classification accuracy (Lebart at al., 2006).

For estimating the probability that a client company is accepted by an audit company, member of the Big 4, according to the factor variables considered in the work hypothesis (H3) we propose the use of $L R A$. The method makes appeal to the regression models with dependent alternative variables, of the form:

$Y=\beta_{0}+\beta_{1} X_{1}+\ldots+\beta_{n} X_{n}+\varepsilon$

Where $X_{i}(\mathrm{i}=1, \ldots, \mathrm{n})$ are independent variables, $\beta_{i}$ the model coefficients (estimated parameters), $Y$ dichotomist variable $(Y=1$ in the case that the client company was accepted by one of the audit companies members of Big 4), and $Y=0$ for the case when it was not accepted by that company) and $\varepsilon$ represents the error component. We must mention the fact that $Y$ is a variable of Bernoulli type (Gujarati, 2004) and associates the values that it can take (one and zero), the occurrence probabilities: $p$ for $Y=1$ and $q$ for $Y=0 . L R A$ starts from the idea that the conditioned average,

$M\left(Y_{i} / X_{i}\right)=p_{i}$

Is based on a logistical distribution: $M\left(Y_{i} / X_{i}\right)=p_{i}=1 /\left[1+e^{(\beta 0+\beta 1 X 1+\ldots+\beta n X n)}\right]=$
$1 /\left(1+e^{-z i}\right)$

Based on the application of the inverse function it will result that

$z_{i}=\ln \left[p_{i} /\left(1-p_{i}\right)\right]$

And the logistic model will be defined by the relation (Gujarati, 2004):

$L_{i}=\ln \left[p_{i} /\left(1-p_{i}\right)\right]=\beta_{0}+\beta_{1} X_{1}+\ldots+\beta_{n} X_{n}+\varepsilon_{i}$

\section{Data Processing Instruments}

For the analysis of data, we used the information product, the statistical software SPSS 19.0.

\section{Research Results and Discussions}

For validating the $\mathrm{H} 1$ hypothesis, the application of $M C A$ on the data from the sample taken into account led to obtaining the customer acceptance criteria, represented with the help of the diagrams from figures 2, 3, 4 and 5 . The manner of interpretation of diagrams takes into account the association between the characteristics of qualitative variables (a proximity between them supposes the existence of a connection). 


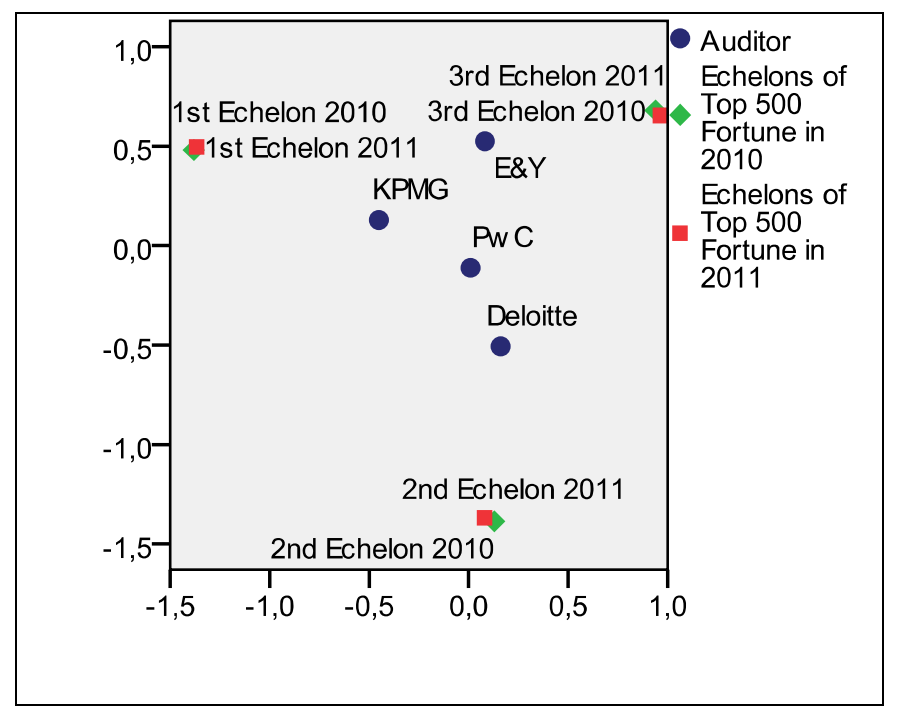

Fig 2. The Association between the Belonging of a Company to One of the Big 4 Companies and the Echelon in Top 500 Fortune 2010 and 2011

(Source: own processing in SPSS 19.0)

Based on the graphical representation of the association between the position of the analyzed companies (in Top 500 Fortune 2011 and 2010) and the belonging to a certain auditor in 2011 we can draw the conclusion that in average, the companies of the first echelon (place 1-30) are accepted to be audited, mainly, by KPMG, the second echelon are audited by Deloitte, and the companies from the third echelon are accepted by E\&Y. PwC accepts however to audit the companies from all the three echelons taken into account. Based on this information, we can draw the conclusion that the prestige of the customer company, reflected through the position occupied in Top 500 Fortune, represents a determinant factor in taking the decision to be or not accepted to audit by one of the Big 4 companies. This fact can be explained through the practice of certain audit companies to avoid the exposal to the risks generated by the acceptance of certain clients.

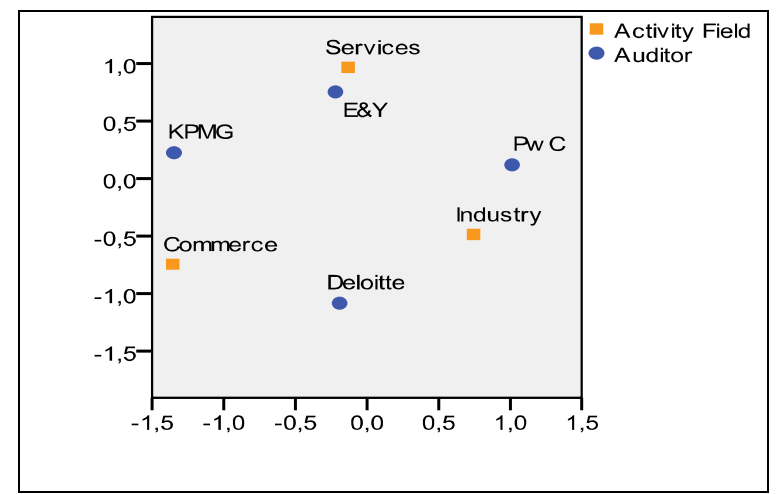

Fig. 3. The Association between the Belonging to One of the Big 4 Companies and the Activity Field of the Client Companies

(Source: own processing in SPSS 19.0)

As regards the association between the belonging of the clients to one of the Big 4 companies and the field of activity, we can notice that at the level of the analyzed samples the audit companies specialized on certain fields, accepting the clients according to this criterion. This denotes also the competence of the financial audit 
companies in certain fields of activity. Thus, we can notice the fact that E\&Y mainly accepts clients from the service field (and less from commerce and industry), $\mathrm{PwC}$ is mainly focused on the industry and service companies (but in a smaller percentage), Deloitte accepts in the same extent companies from commerce and industry and KPMG is specialized on the auditing of service and commerce companies.

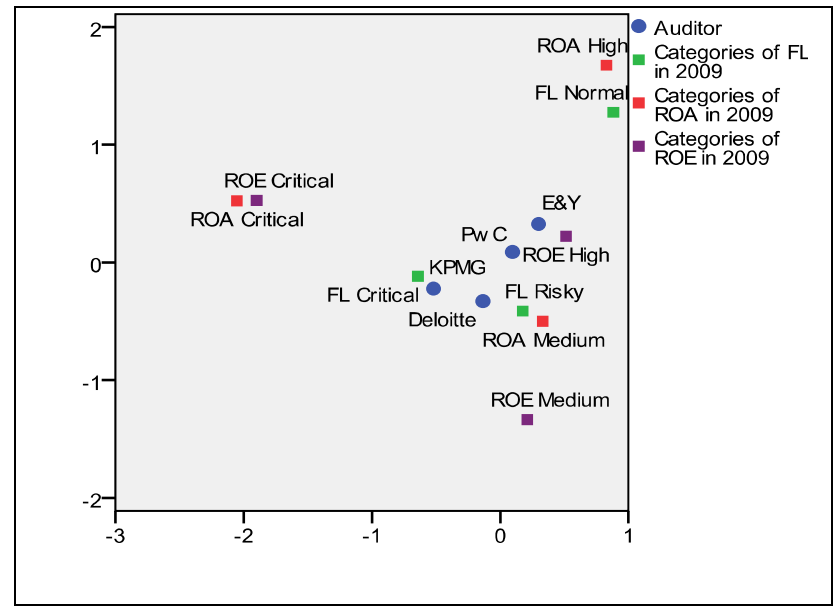

Fig. 4. The Association between the Belonging to One of the Big 4 Companies and the FL, ROA and ROE Levels

(Source: own processing in SPSS 19.0)

The influence of the client's position and financial performance on the acceptance decision to be audited by one of the Big 4 companies is emphasized through the diagram from figure 4 . Thus, we appreciate the fact that at the level of the analyzed sample the financial profile of the client company is characterized by an average level of $R O A$, a critical or risky $F L$ and a level above the average of $R O E$. Moreover, although we notice a high debt degree at the level of the client companies accepted, the use of resources attracted in the operational activities leads to obtaining superior results, which leads to registering average values of $R O A$ and above average of $R O E$. This emphasizes the fact that the Big 4 audit companies refuse to audit companies that cannot continue their activity in a predictable horizon of time, the associated risk Going Concern (ISA 570, IFAC 2010) being a basic criterion based on which the auditor's decision to accept a client is taken.

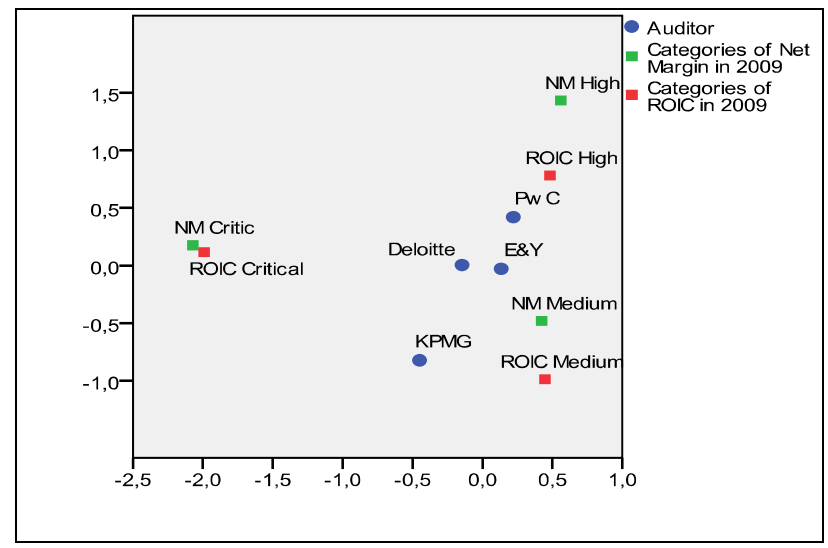

Fig. 5. The Association between the Belonging to One of the Big 4 Companies and the NM and ROIC Levels

(Source: own processing in SPSS 19.0) 
Not lastly, the influence of the client's financial performance on the acceptance decision by one of the Big 4 companies can be also emphasized through the association between the different levels of $N M$ and ROIC and auditor. Thus, we can appreciate the fact that the audit companies from Big 4 accept the clients with $\mathrm{NM}$ and ROIC average and above average levels. In this case as well, the decision is influenced by the client's capacity to continue his activity, above average values of $N M$ and ROIC emphasize the fact that the investments made by the client ensure the obtaining of a merchantable production, which allows registering profit.
Although the study of the association between the financial and non-financial indicators allows the identification of a client acceptance profile for each company member of Big 4, the punctual influence on the auditor's decision can only be estimated with $D A$ and $L R A$.

The application of $A D$ on the data from the analyzed sample (profitability rates, $L F$ and the position occupied in the previous year before the acceptance by the auditor (in SPSS we obtained a series of descriptive statistics analyzed in Table 3.

Table 3: Descriptive Statistics of the Variables Taken into Account in the Study

\begin{tabular}{|l|l|l|l|l|l|l|l|l|l|l|}
\hline & \multicolumn{2}{|c|}{ E\&Y } & \multicolumn{2}{c|}{ KPMG } & \multicolumn{2}{c|}{ PwC } & \multicolumn{2}{c|}{ Deloitte } & \multicolumn{2}{c|}{ Big 4 } \\
\hline Variable & Mean & St.D & Mean & St.D & Mean & St.D & Mean & St.D & Mean & St.D \\
\hline $\begin{array}{l}\text { Top500F } \\
\text { 2010 }\end{array}$ & $\mathbf{5 5 . 5}$ & 35.4 & $\mathbf{4 6 . 8}$ & 29.5 & $\mathbf{5 3 . 7}$ & 34.0 & $\mathbf{7 0 . 6}$ & 92.3 & $\mathbf{5 7 . 6}$ & 55.2 \\
\hline R0A'09 (\%) & $\mathbf{5 . 7}$ & 6.0 & $\mathbf{2 . 5}$ & 7.7 & $\mathbf{5 . 5}$ & 5.3 & $\mathbf{5 . 9}$ & 19.9 & $\mathbf{5 . 2}$ & 11.4 \\
\hline ROE'09 (\%) & $\mathbf{6 . 5}$ & 48.3 & $\mathbf{2 . 3}$ & 34.0 & $\mathbf{5 . 9}$ & 67.2 & $\mathbf{1 4 . 2}$ & 15.7 & $\mathbf{7 . 7}$ & 92.2 \\
\hline $\begin{array}{l}\text { ROIC'09 } \\
\text { (\%) }\end{array}$ & $\mathbf{9 . 5}$ & 11.4 & $\mathbf{4 . 9}$ & 12.5 & $\mathbf{- 1 . 6}$ & 62.8 & $\mathbf{- 1 . 1}$ & 144.9 & $\mathbf{2 . 6}$ & 81.2 \\
\hline NM'09 (\%) & $\mathbf{5 . 9}$ & 8.5 & $\mathbf{3 . 4}$ & 6.9 & $\mathbf{2 . 3}$ & 35.8 & $\mathbf{- 6 2 . 0}$ & 33.5 & $\mathbf{- 1 3 . 3}$ & 20.0 \\
\hline FL'09 & $\mathbf{8 . 9}$ & 33.1 & $\mathbf{4 . 8}$ & 3.5 & $\mathbf{1 0 . 2}$ & 35.74 & $\mathbf{2 . 9}$ & 14.2 & $\mathbf{7 . 1}$ & 27.3 \\
\hline
\end{tabular}

Based on the data synthesized in table 3, with a probability of $95 \%$ we can say that, in average, a client accepted by an audit company member of Big 4 occupies position 57- 58 in Top 500 Fortune in 2010 (based on the financial statements of 2009) and presents a value of $R O A$ of $5.17 \%$, of ROE of $7.72 \%$ of ROIC of $2.58 \%, N M$ of $13.26 \%$ and a $F L$ of 7.13 . Moreover, the clients who occupy, in an average, leading positions in the mentioned top (the first 46) are audited by KPMG, and those occupying the last positions by PwC. At the ROA level, the clients with the highest average value of this indicator (5.9\%) are audited by Deloitte, and with the smallest value $(2,5 \%)$ by KPMG.

For the $R O E$ indicator, the highest average value $(14.2 \%)$ is registered by the companies audited by Deloitte, and the smallest the companies audited by KPMG. At the ROIC level, the companies audited by E\&Y register the highest average value of this indicator $(9.5 \%)$ and those audited by $\mathrm{PwC}$ register the smallest average value $(-$ $1.6 \%)$. For NM, we appreciate that the highest average value (5.9\%) is registered by the companies audited by E\&Y, and the smallest average value by the companies audited by Deloitte (-62\%).

As regards FL, the least indebted companies are those audited by Deloitte (2.9) and the companies with the highest debt degree are audited by PwC (10.2). Of the information presented above, we can notice the tendency of the audit companies to accept their clients according to the risk assumed regarding their capacity to continue their activity, this being also a criterion supporting the acceptance decision.

The DA advantage is represented by the obtaining of client classification functions according to the punctual values of the variables taken into account in the analysis. 
More than that, by estimating the coefficients from the model we determine also the importance that a certain indicator has when making the discrimination.
In Table 4, we present the functions of classifications of clients for each auditor, according to the values of the factor variables taken into account.

Table 4: Coefficients of Classification Functions

\begin{tabular}{|l|l|l|l|l|}
\hline & \multicolumn{4}{|c|}{ The coefficients of the classification functions afferent to each } \\
auditor
\end{tabular}

(Source: own processing in SPSS 19.0)

For obtaining every classifying function one will proceed to aggregating the product between every coefficient and every variable, according to the model:

$\mathrm{Z}_{\mathrm{E \& Y}}=-2.19+0.02$ Top $_{500 F 2010}+0.12 \mathrm{ROA}-0.01 \mathrm{ROE}-0.02 \mathrm{ROIC}+0.01 \mathrm{NM}+0.01 \mathrm{FL}$

In the same way one will proceed too for the classifying functions of the other audit companies from Big 4. The main advantage of these functions is the accomplishment of classifications for the companies which are not included in the sample, or the financial situations of the same companies from the sample. The usage mode of the classifying functions is relatively simple and appeals to the following reasoning: for the company that it will be desired to be classified (it is desired knowing the auditor which will accept it for auditing) it will be replaced in every of the 4 models, the indicator's values within the acceptance decision, and a score will be obtained. The maximum value of the obtained score on one of the 4 functions will dictate the affiliation to a certain auditor. Moreover, according to the coefficients' value, but also to their sign, it can also be appreciated the importance of every indicator within the acceptance decision, for every auditor apart. Thus, for example, it can be observed that for the acceptance of a client E\&Y gives the highest importance $R O A(0.12)$ and less ROIC (-0.2).

In what concerns the $L R A$ implementation, in table 5 are synthesized the main results obtained in SPSS for obtaining the probability of being accepted by one of the audit companies, member of Big 4 .

Table 5: Results Obtained in LRA for Determining the Acceptance Probabilities

\begin{tabular}{|l|l|l|l|l|l|l|l|l|}
\hline & \multicolumn{2}{|c|}{ E\&Y } & \multicolumn{2}{c|}{ KPMG } & \multicolumn{2}{c|}{ PwC } & \multicolumn{2}{c|}{ Deloitte } \\
\hline Variables & $\boldsymbol{\beta}_{\boldsymbol{i}}$ & $\exp \left(\boldsymbol{\beta}_{\boldsymbol{i}}\right)$ & $\boldsymbol{\beta}_{\boldsymbol{i}}$ & $\exp \left(\boldsymbol{\beta}_{\boldsymbol{i}}\right)$ & $\boldsymbol{\beta}_{\boldsymbol{i}}$ & $\boldsymbol{\operatorname { e x p }}\left(\boldsymbol{\beta}_{\boldsymbol{i}}\right)$ & $\boldsymbol{\beta}_{\boldsymbol{i}}$ & $\exp \left(\boldsymbol{\beta}_{\boldsymbol{i}}\right)$ \\
\hline Top500F-2010 & 0.00 & 1.00 & -0.01 & 0.99 & -0.01 & 0.99 & 0.01 & 1.00 \\
\hline R0A'09 (\%) & 0.06 & 1.06 & -0.11 & 0.90 & 0.05 & 1.06 & -0.03 & 0.97 \\
\hline R0E'09 (\%) & -0.02 & 0.98 & -0.02 & 0.98 & 0.00 & 1.00 & 0.01 & 1.01 \\
\hline R0IC'09 (\%) & 0.01 & 1.01 & 0.04 & 1.04 & -0.02 & 0.98 & -0.01 & 1.00 \\
\hline NM'09 (\%) & 0.01 & 1.01 & 0.02 & 1.02 & 0.01 & 1.00 & -0.03 & 0.97 \\
\hline FL'09 & -0.01 & 0.99 & -0.03 & 0.97 & 0.00 & 1.00 & -0.02 & 0.98 \\
\hline Industry & -0.52 & 0.59 & -0.47 & 0.63 & 0.49 & 1.63 & -0.05 & 0.96 \\
\hline Commerce & -0.25 & 0.78 & 0.38 & 1.46 & -0.83 & 0.44 & 0.32 & 1.38 \\
\hline Constant & -0.71 & 0.49 & -0.82 & 0.44 & -1.02 & 0.36 & -1.30 & 0.27 \\
\hline
\end{tabular}

(Source: own processing in SPSS 19.0) 
Starting from the obtained results in SPSS in Table 5, the equation according to which it will be determined the probability that a client be accepted by the E\&Y will be in the form:

\footnotetext{
$\operatorname{In}\left[p_{E \& Y} /\left(1-p_{E \& Y}\right)\right]=-0.71+0,00$ Top $_{500 F 2010}+0.06 R O A-0.02 R O E+0.01 R O I C+0.01 N M+$ $0.01 F \boldsymbol{L}-0.52 \mathbf{D}_{\text {Industry }}-0.25 \mathbf{D}_{\text {Commerce }}$

And similarly it will also be proceeded for obtaining the associated models and of the other audit companies, member of Big 4. In the present case, it can be observed that the chance a company would be audited by E\&Y and not the other companies from Big 4 is positively influenced by the $R O A, R O I C$ and $N M$ level, and it is decreased by the $R O E$, FL levels, the affiliation to the industrial and commerce fields (the chance rises - in logarithm, if the company is from services). In respect that, at the proposed model level, the growth with a unit of the factor variable, determines a variation in logarithm of the chance to be or not to be accepted by E\&Y, it is entailed the use of the coefficient from the model under exponential form. Therefore, at a growth of $1 \%$ of $R O A$, the chance that the company be accepted by E\&Y and not the other companies of Big 4 rises 1.06 times.

From the analysis of the coefficients' models of acceptance probability determination and for the other companies in Big 4 it can be observed that for KPMG, ROIC, NM and the affiliation to the commerce field contributes to the growth of the chance of being accepted by this audit company. For $\mathrm{PwC}$, values of $R O A$, $R O E, N M, F L$ and the affiliation to the industrial field contributes to the growth of the chance of being accepted by it, and for Deloitte, indicators as the position in Top 500 Fortune, ROE, ROIC and the affiliation to the commerce field significantly contributes to the growth of chances of being accepted by it.

According to the up mentioned, we believe that the use of MCA, DA and LRA for obtaining acceptance profiles, classifying functions, but also chance determination models, under the form of analytical procedures that will support the auditor's decision of acceptance or not of a company according to a series of predetermined criteria.

\section{Conclusions and Future Research}

In the context of the current economic crisis, marked by the instability of the financial markets, frauds and lack of transparency in the financial report, the auditor's opinion is more than of a statutory character, but an imperious one. The auditor must give to every stakeholder the assurance of a fair view of the financial statements of the quoted companies, according to the audit report.

Last but not least, the auditor must maintain to a high rate the level of professionalism, independence, and objectivity and also posture. For this, according to certain factors which it can identify to a certain client (integrity, reputation, the capacity to continue its activity, profitability), but also according to its capacity (specialization in a certain field, professional training), the auditor can decide the acceptance of the company to be audited or not, avoiding the exposure to certain inherent risks of control or of undetection with an impact on the audit risk.

After validating the three working hypothesis, it can be asserted that by using analyzing methods of proposed data for study a series of profiles can be obtained (of financial and non-financial nature), of classifying functions, but also of chance assessment that a client be accepted or not by one of the Big 4 member companies. These profiles and models can also be used for companies which are not included in the sample (or for future financial exercises) in order to sustain the auditor's decision.

From the obtained results it can be observed that some Big 4 member companies lay an emphasis on certain profitability rates for accepting clients, or on the debt rates, evaluating also this way (although preliminary) the client's capacity to continue its activity, in compliance with 
ISA 570. Still, other audit companies lay the emphasis on the reputation of the client companies and on the positions these have in the performance tops made at an international level (Top 500 Fortune). Last but not least, it has been observed that a very important criterion is represented by the activity object of the client, thus the audit companies specialize to this purpose on certain fields, a reason for which the accumulated experience influences the acceptance of the client.

We believe that the here study brings a series of contributions in what concerns the factor analysis which determine the acceptance of the client by the auditor, according to a series of financial and nonfinancial factors, conferring a concrete answer to the problems arisen in the specialty practice.

The study limits are generated by the focus on only a certain number of analyzed companies, but in the future it is desired the enlargement of the sample. Moreover, we wish that in the future studies we also include other indicators in the proposed models and even to particularize them on the case of the Romanian companies, rated at the Bucharest Stock Exchange.

Last but not least, the usage of the statistical methods within the financial audit mission, and also the interconnection of their results with the financial analysis and accountancy can open a new research direction. This new field that is desired to analyze the economic-financial phenomenon within the financial audit according to some indicators from the financial analysis through statistical and econometric advanced methods, we denominate it hypothetically auditometrics.

\section{Acknowledgements}

This work was supported by the the European Social Fund in Romania, under the responsibility of the Managing Authority for the Sectoral Operational Programme for Human Resources Development 2007-2013 [grant POSDRU/CPP 107/DMI 1.5/S/78342].

\section{References}

Amernic, J. \& Craig, R. (2004). "Reform of Accounting Education in the Post-Enron Era: Moving Accounting 'Out of the Shadows'," Abacus 40 (3), 342-378.

Arens, A., Elder, R. \& Beasley, M. (2012). 'Auditing and Assurance Services: An Integrated Approach,' 14th edition, Pearson Education, New Jersey.

Ball, R. (2009). "Market and Political/ Regulatory Perspectives on the Recent Accounting Scandals," Journal of Accounting Research 47 (2), 277- 323.

Basioudis, I. G. (2007). "Auditor's Engagement Risk and Audit Fees: The Role of Audit Firm Alumni," Journal of Business Finance and Accounting 34 (9), 1393-1422.

Beattie, V., Fearnley, S. \& Brandt, R. (2004). "A Grounded Theory Model of AuditorClient Negotiations," International Journal of Auditing 8, 1-19.

Bragg, S. M. (2007). Financial Analysis. A Controller's Guide, 2nd ed., John Wiley \& Sons, New Jersey

Bragg, S. M. (2010). 'Practitioner's Guide to GAAS 2010 Including all SASs, SSAEs, SSARSs, and Interpretations, \John Wiley \& Sons, New Jersey

Brenda, P. \& Jon, S. (2003). 'Principles of External Auditing, second edition, John Willey \& Sons LTD, West Sussex.

Dowler, F., Harris, E. M. (1912). 'Auditing, Accounting and Banking,' Sir Isaac Pitman \& Sons, London

Ebaid, I. E.- S. (2011). "Corporate Governance Practice and Auditor's Client Acceptance Decision: Ecpirical Evidence from Egypt," Corporate Governance 11 (2), 171-183.

Fabozzi, F. J. \& Peterson, P. P. (2003). Financial Management and Analysis, 2nd ed., John Wiley \& Sons Inc, New Jersey. 
Fukukawa, H., Mock, T. J. \& Wright, A. (2011). "Client Risk Factors and Audit Resource Allocation Decisions," ABACUS 47 (1), 85- 108.

Gendron, Y. (2001). "The Difficult Client Acceptance Decision in Canadian Audit Firms: A Field Investigation," Contemporary Accounting Research 18 (2), 283-310.

Greenstein, M. M. \& Hamilton, D. M. (1997). "Critical Factors to Consider in the Development of an Audit Client Engagement Decision Expert Support System: A Delphi Study of Big Six Practicing Auditors," Inteligent Systems in Accounting, Finance and Management 6, 215-234.

Gujarati, D. N. (2004). 'Basic Econometrics,' the McGraw-Hill Companies, New York.

Hayes, R., Dassen, R., Schilder, A. \& Wallage, P. (2005). Principles of Auditing. An Introduction to International Standards of Auditing, 2nd edition, Pearson Education.

Hellman, N. (2011). “Chief Financial Officer Influence on Audit Planning," International Journal of Auditing 1, 1-28.

International Federation of Accountants IFAC (2009). 'International Standards on Auditing,' New York.

International Federation of Accountants IFAC (2010). 'Good Practice Guide: Client Acceptance and Continuance,' New York.

Jaba, E. \& Grama, A. (2004). 'Analiza Statistică cu SPSS sub Windows,' Ed. Polirom, Iaşi.

Jaba, E. \& Robu, I. B. (2009). "Utilizarea Analizei Discriminant Pentru Obţinerea Probelor de Audit," Audit Financiar 7 (11), 20-24.

Johnstone, K. M. (2008). 'Client-acceptance Decisions: Simultaneous Effects of Client Business Risk, Audit Risk, Auditor Business Risk, and Risk Adaptation,' Auditing Sarasota, Spring 19 (1), 1-25.

Lebart, L., Piron, M. \& Morineau, A. (2006). Statistique

Exploratoire
Multidimensionnelle. Visualisation et Inférences en Fouille de Données, 4e édition, Dunod, Paris.

Limperg institute (1985). 'The Social Responsibility of the Auditor,' Amsterdam.

McFadden, J. E. (2003). 'Client and Engagement Acceptance: Only a Public Company Audit Service Concern?,' The Practicing CPA, 27(6), rmr3-rmr4.

Mironiuc, M. (2006). 'Analiză EconomicoFinanciară. Elemente TeoreticoMetodologice şi Aplicaţii,' Sedcom Libris, Iaşi.

Niemi, L. (2002). “Do Firms Pay for Audit Risk? Evidence on Risk Premiums in Audit Fees after Direct Control for Audit Effort", International Journal of Auditing 6, 37-51.

Penman, S. H. (2007). Financial Statement Analysis and Security Valuation, 3rd edition, McGraw Hill.

Pfeffer, J. \& Salancik, G. R. (1978). The External Control of Organizations: A Resource Dependence Perspective, Harper \& Row, New York.

Pickett, K. H. S. (2006). Audit Planning: A Risk-Based Approach, John Wiley \& Sons Inc, New Jersey.

Soltani, B. (2003). 'Auditing: An International Approach,' Prentice Hall, Pearson Education, Essex.

Stevenson, J. E. (2002). "Auditor Independence: A Comparative Descriptive Study of the UK, France and Italy", International Journal of Auditing 6, 155-182.

Walsh, C. (2003). Key Management Ratios. Master the Management Metrics that Drive and Control Your Business, Prentice Hall, London.

Watts, R. L. \& Zimmerman, J. L. (1978). 'The Demand for and Supply of Accounting Theories: The Market for Excuses,' The Accounting Review (April), 273-305. 